\title{
Research on Collaborative Innovation and English Teaching in Higher Vocational Colleges
}

\author{
Danlu Liao ${ }^{1, a}$, Fongpeng Chew $^{2, b}$ \\ ${ }^{1}$ Chongqing Vocational Institute of Tourism, Chongqing, China \\ ${ }^{2}$ Malaya University, Kuala Lumpur, Malaysia \\ a871540023@qq.com, bfpchew@um.edu.my
}

Keywords: Collaborative Innovation, Higher Vocational Colleges, English Teaching

\begin{abstract}
In the case of English education in higher vocational colleges, collaborative innovation is the trend of development. The students who are trained by traditional higher vocational English teaching have been unable to meet the needs of the employers in today's society. Therefore, it is necessary to promote the system construction of the conception "Cultural education, Compound education and Cooperative education" through collaborative innovation. We should strengthen the professional ability of higher vocational students, career change ability, social adaptability and entrepreneurial innovation ability, and develop a group of high-level application talents with professional technical ability.
\end{abstract}

\section{Introduction}

In recent years, China attaches great importance to the concept of "collaborative innovation" in education. Chairman $\mathrm{Hu}$ Jintao put forward the concept of "coordinated innovation" in the centennial celebration of Tsinghua University. This is the first time in our country's history to put forward the requirements of collaborative innovation at the national level for universities, scientific research organizations and related industries [1]. Then, in 2012, the Ministry of education and the Ministry of finance jointly issued the opinions on the implementation of the plan for the improvement of innovation capacity in institutions of higher learning, and launch the "higher school innovation capacity promotion program" (" 2011 plan ") project. As a starting point, China has officially started to promote collaborative innovation in relevant fields. Among them, higher vocational public English is a course with definite orientation, and its goal is to cultivate professional talents. Therefore, the course content should be carried out around this goal, and it needs to be prepared for the development of students' professional abilities [2]. On March 4, 2013, $\mathrm{Xi}$ Jinping delivered an important speech at the 12th national committee of the Chinese people's political consultative conference (CPPCC), stressing the need to unswervingly follow the path of independent innovation with Chinese characteristics. He pointed out that the innovative development strategy is an important strategy based on the holistic view and the outlook of the future. It will promote the change of economic development pattern and solve the problems brought by economic development, and become an important driving force for economic development. Therefore, we should always make overall planning, adhere to collaborative innovation, constantly improve the innovation atmosphere, and persistently promote innovative development.

These important discourse about the collaborative innovation has very important guiding significance for China to implement the strategy of rejuvenating the country through science and education, building an innovation-oriented country, strengthening the quality of personnel training, improving scientific research ability, promoting social development and maintaining cultural heritage. It also points out the new development direction for education development and reflects the core concept of cooperative education in vocational education. Therefore, the English teaching in higher vocational colleges should be guided by social needs and cultivate students into active 
participants and promoters of social and economic development.

\section{The Generation of Collaborative Innovation}

The birth of the idea of coordinated innovation can be traced back to the idea of mutual infiltration between teaching and research in the 19th century. The first person to carry out this great idea of combine teaching with science was Humboldt at the University of Berlin in Germany. He pointed out that teachers need to engage in certain scientific research in addition to completing the established teaching work, so as to constantly learn new knowledge and to teach the students better. In addition, students should also cooperate with teachers' scientific research and develop innovative practices in the guidance of teachers (1810). Under such an academic background, American colleges and universities in the last century began to implement the teaching method of integrating teaching and science, and therefore established a system of training for education and scientific research. Universities and enterprises realize the optimal allocation of resources and achieve a win-win situation. It was also a manifestation of the idea that Britain's "cooperation education" or "sandwich" teaching adopted in the early 20th century. From the above examples, we can see the epitome of "collaborative innovation". The original form of the combination of teaching and research in China can be traced back to the ideas of combine teaching, production and scientific research proposed in the 1950s, but they almost emphasize "cooperation" rather than "collaboration".

On the connotation of "collaborative innovation", it is widely accepted that Peter Gloor, a researcher at education, defines it: A group formed by people with common goals to work together through network information and have a positive attitude towards achieving a unified goal [3]. It has been found that this concept is often used in the sharing mechanism of enterprises, and the people involved in it generally have a unified goal. They communicate and cooperate fully through the relevant platform of modern information technology. The development of such activities has led to the implementation of collaborative innovation in academic research in several countries. Therefore, a collaborative regional innovation network centered on high-tech, scientific research organizations and related enterprises has been formed, forming a virtuous cycle of mutual promotion between science technology and industry. "Collaborative innovation" is committed to making breakthroughs in the subject of innovation. Through the permeation and mutual integration between the elements of innovation, the potential and vitality of each element can be fully realized. Thus, the effective coordination and cooperation of different social bodies can be formed, and chemical reactions can be produced by physical combination.

\section{Collaborative Innovation and Higher Vocational Education.}

Higher vocational education is responsible to training high-level skilled application talents for the production and operation, management and service of the first-line. It is characterized by professionalism, directness, practicality and flexibility. This brings the elements of production and industry into the talent cultivation mode of universities. It advocates the close connection between teaching activities and life practice, and then strengthens the practicability of collaborative innovation and expands its application scope. This will also greatly promote the development of enterprises and regional economies. (Hu Chunlin, 2012).

On the one hand, the collaborative innovation of education in higher vocational colleges should strengthen cooperation with related trades and industries in order to cultivate the strategic emerging industries and promote the traditional industries, then application of science and technology in supporting the development of industries can be realized. On the other hand, we should also be based on regional development, adhere to the economic and social development as a center of work. We can also cooperate with local enterprises or R\&D units to jointly promote regional innovation process. To further implement the strategy of collaborative innovation, higher vocational colleges can carry out systematic reform of education through the way of "Cultural education, Compound 
education, Cooperative education "and comprehensively promote the reform of the training of highly qualified and highly skilled personnel.

\subsection{Cultural Education}

One of the most important parts of education in higher vocational colleges is "cultural education". This is not only a cultural edification of our original cognition, but also a dynamic and sustainable educational process and cultural process. The "Culture" here is both a means and a purpose. "Cultural education" covers a wide range, including education, management and environment. Students should take active learning and positive thinking in a harmonious cultural atmosphere, so as to experience the feeling of life, learn how to be human and improve themselves comprehensively.

One of education priority in universities is to realize the communication and progress between cultures. Higher vocational colleges should actively carry out cultural exchanges with other countries. The single special skill education has not adapted to the needs of rapid economic and social development. Higher vocational colleges should focus on the quality of professional culture and focus on guiding students to develop correct professional ethics and comprehensive quality. Let students develop a responsible character in the future work.

\subsection{Compound education}

Higher vocational colleges should adopt the idea of "compound education" and transform education teaching concept. Take the students as the fundamental and the social needs as the orientation, the colleges should actively adapt to the challenge of the higher and higher requirements of the industrial structure and the talent training. We should take the guidance of quartet joint action of government-school-industry-enterprise and the stereo propulsion of industry-university-research-application, emphasize on the compound combination as the focus of the work to promote the reform of the teaching system, think how to optimize students' professional quality, encourage students to acquire the knowledge they need through independent study, find out the training programs which is suitable for the needs of times, guide students to establish correct values, and realize the effective competition and adaptation of students in the society. Therefore, it is necessary to ensure that students have certain professional skills and professional qualities, so as to help students to better adapt to various challenges in the society in the future. That is to say, we should break through the limitation of previous only raise students' ability to unilaterally career change, cultivate students' professional ability and psychological quality through targeted and complex professional courses. Thus can it help them to adapt to the future social competition.

\subsection{Cooperative education}

Cooperative education is an important part of the whole theoretical system. Its definition is that under the guidance of the government, universities, scientific organizations and related enterprises share resources within the system to achieve talent training and knowledge appreciation, so as to achieve the purpose of personnel training and use. In order to optimize the training mode and design innovative talent training program, colleges and universities should carry out active and effective cooperation with redundant scientific research organizations and relevant enterprises, set up an interdisciplinary teaching and research team, give full play to the advantages of resources, realize the task of personnel training and promote the improvement of innovation ability. Aiming at cultivating innovative talents, we should focus on improving students' scientific research practice ability, and strive to realize the mutual support of high level scientific research and high-quality talent cultivation. The parties to "collaborative innovation" should establish the concept of open cooperation, strive to break through the traditional mechanism, and implement synergetic mechanism in the aspects of cultivation mode, teaching philosophy, resource allocation and management. 


\section{Collaborative Innovation and English Teaching in Higher Vocational Colleges}

English teaching in higher vocational colleges is intercultural and communicative, and plays an important role in cultural education. For collaborative innovation of higher vocational English teaching, therefore, we should make use of a single language teaching into a creative culture, highlighting the cultural education value of the discipline should contain, cultivate students to be able to communicate in different cultural perspectives, strengthening student's concept of cultural self-confidence and inheriting Chinese excellent traditional culture. All these are the essential embodiment of the function of higher vocational English teaching culture.

\subsection{Strengthen the Concept of "Cultural Education" and Enrich the Content of Cultural Teaching.}

In the specific "cross-cultural" teaching, we should not only pay attention to develop the student's ability of language communication, but also focus on the education work about training students in the way of thinking, moral character and values. The connotation of Chinese traditional culture is extensive, which is also an important aspect of "cultural education" in higher vocational English teaching. Therefore, in higher vocational English education, we should enhance our understanding of the connotation of China's excellent traditional culture. Opening the course of Chinese culture introduction in English to prevent students from developing "Chinese cultural aphasia" In specific teaching process, on the one hand, we should let students understand the cultural background of the point, cultivate their cultural ability, can this improve their communication based on the holistic view of different cultures. On the other hand, students should also make more comparisons between different cultures, learn the essence of foreign cultures, and summarize the cultural laws on the basis of this.

For teachers, it is necessary to use the information-based teaching method to make full use of the advantages of modern education technology in teaching cultural knowledge. For example, through multimedia resources, teachers can show students rich and diverse language and culture teaching environment, guide students to acquire new cultural knowledge in a harmonious and relaxed learning atmosphere. This can help students to enrich their cultural reserves. In addition, teachers should also pay attention to the diversity of classroom activities. For example, students can be divided into two groups to debate and analyze a hot topic. In this way, we can provide various channels to guide students to understand various cultures and their related knowledge in a comprehensive way and enhance their cultural literacy.

\subsection{Play an important role in the main channel of classroom teaching, professional ideas promote cultural education.}

We should carry out professional education through the daily teaching, carry out the philosophy and values education from the aspects of thinking, ability and attitude, and teach students how to develop the professional quality. It is necessary to strengthen the intercultural teaching of English in higher vocational colleges and improve the communication ability of students in different cultural backgrounds. Further integrate and develop the education curriculum module of cultural quality, and offer a variety of special culture courses. Offer cultural courses such as "International Tourism Culture English", "Appreciation of English Films from The Perspective of History and Culture", "English National Society and Culture", etc. By infiltrating the professional culture education into the classroom teaching process, strengthening the connection between professional knowledge and skills and professional spirit, combining the professional culture of education in higher vocational education, thus further standardizing the students' professional quality.

\subsection{Establish the cultural education concept of mutual penetration of professional knowledge and cultural quality.}

We should strengthen the reform and innovation of teaching management and education management, unify the knowledge and culture, and try to cultivate the cross-culture elite from the 
aspects of the course construction, the teaching content, the graduation thesis design, the teaching method renewal, the teaching effect evaluation and so on. It is possible to cultivate compound innovative high - quality talents with professional courses such as school choice expansion, inter-school binding extension and college expansion. Furthermore, we should explore workplace English teaching and carry out "compound education" and cultivate English talents in higher vocational colleges through the combination mode of "English + development". Take "make good language foundation, improve application ability, contact work position, reflect career development" as the teaching goal, the course system is divided into four stages: Basic English, workplace English, industry English and professional English. Try to use the work process as a guide to vocational English teaching, and establish a public English certificate system for each stage.

\subsection{Set up the "guidance committee on industry-university-research-application" and carry out the "studio" practice teaching mode with task-oriented.}

The guidance committee on industry-university-research-application is mainly responsible for the daily teaching and scientific research of English. We should carry out special skill training in English teaching, for example, set up "translation studio". The teacher should arrange a reasonable amount of reading task for the students in the studio, and provide the translation task and oral training task of the corresponding situation. In this way, students can better accept interpret exercise, develop their communication skills and on-site interpretation services.

For English teaching in higher vocational colleges, the collaborative innovation in this field should strengthen the relevant hardware and software construction and improve the relevant infrastructure in the school. In addition, the school should also set up an off-campus practice base to provide students with professional practice and post internship activities. And through the guidance of policies and programs, organically combined with the education teaching and personnel training, scientific and technological innovation, production and social services, actively carry out different levels, different types, different forms of collaborative innovation. At the same time, the college can carry out overseas internships, and regularly organize students to practice their language skills in overseas enterprises. In this way, students can obtain the experience of international business practice and lay a solid foundation for their ability to work in foreign-related enterprises after graduation.

\subsection{Adhering to the school-running idea of "Government - university - industry - enterprise quartet joint action and industry-university-research-application stereoscopic promotion".}

In order to realize the strategic goal of collaborative innovation, education in higher vocational college should be truly adapted to the needs of the times and adapt to the challenges posed by the innovation era. Focusing on the major needs of national strategy and regional development, take the training reform of the complex innovative high-quality talents as the work core. Put the construction of teaching staff in a prominent strategic position, promote the reform of compound innovative talents training, and improve the quality of education in higher vocational English [4].

"Be international, be international man first." Education in higher vocational college should be in line with the international standards, and boldly refer to the typical model of education production and research in developed countries and regions, this includes "cooperative education model" of the United States, the FH and BA education mode of Germany, Australia TAFE education mode, Britain's "sandwich" education mode, Japan's "production" education mode and Taiwan "co-operative education mode. Strengthen cooperation with foreign applied universities in talent training, teacher development, curriculum setting and development. Focusing on the theoretical research and development trend of cooperative education abroad, we should guide the practice of education in higher vocational English with theoretical knowledge and keep innovating. 


\section{Conclusion}

Collaborative innovation is the main strategy for the development of education in China in the future. The practical demands are urgent and the reality is significant, which will provide valuable development opportunities for the vocational English education. The English teaching in higher vocational colleges should pay more attention to the embodiment of scientific training mode, and strive to promote the corresponding system construction and optimize the resource allocation, promote the reform of "cultural education, compound education and cooperative education", and establish a new capacity view. Strengthening the students' professional learning effect, the formation of students' professional quality, help students better adapt to all sorts of challenges in the society in the future. In this way, we can develop more interdisciplinary talents with both English and professional skills.

\section{Acknowledgement}

Research Program "the Innovation of Mixed Teaching Mode in English Based on Mobile Technology in Higher Vocational Colleges(2017-ZJXH-19013)”, Chongqing Vocational Education Society; "the Development Path of Profession Serve Industry in Higher Vocational Colleges: A case study of Tourism English Specialty(2018QZJ169)”, Planning Leading Group of the National Vocational Education Office.

\section{References}

[1] Hu Jintao's speech at the 100th anniversary of the founding of Tsinghua University [N]. People's Daily, 2011-04-25.

[2] Opinions of the Ministry of education and the Ministry of finance on the implementation of the innovation capability improvement plan of institutions of higher learning. [OL]. http://www.moe.gov.cn/srcsite/A16/kjs_2011jh/201205/t20120504_172764.html

[3] Xue Chuanhui. Research on the collaborative innovation strategy of institutions of higher learning II[J]. Contemporary education science. 2012,(7) : 29-31.

[4] Liu Hongyi. Government - university - industry - enterprise quartet joint action and industry-university-research-application stereoscopic promotion. Higher engineering education research, 2009, (3): 115-120. 